\title{
Hannah Arendt's Prognostication of Political Animus in America: Social Platforms, Asymmetric Conflict, and an Offset Strategy
}

\author{
Thomas J. Papadimos ${ }^{1 *}$, Stanislaw P. Stawicki ${ }^{2}$ \\ ${ }^{1}$ Department of Anesthesiology, Division of Critical Care Medicine, The Ohio State University Wexner Medical Center, \\ Columbus, $\mathrm{OH}$, USA \\ ${ }^{2}$ Department of Research \& Innovation, St. Luke's University Health Network, Bethlehem, PA, USA \\ Email: *Thomas.Papadimos@osumc.edu, Stanislaw.Stawicki@sluhn.org
}

How to cite this paper: Papadimos, T. J., \& Stawicki, S. P. (2021). Hannah Arendt's Prognostication of Political Animus in America: Social Platforms, Asymmetric Conflict, and an Offset Strategy. Open Journal of Philosophy, 11, 85-103.

https://doi.org/10.4236/ojpp.2021.111008

Received: November 25, 2020

Accepted: January 30, 2021

Published: February 2, 2021

Copyright $\odot 2021$ by author(s) and Scientific Research Publishing Inc. This work is licensed under the Creative Commons Attribution International License (CC BY 4.0).

http://creativecommons.org/licenses/by/4.0/

\begin{abstract}
In her book, On Violence, Hannah Arendt addresses the events she was witness to in the 1960s. Arendt presents theories on violence through a historical context and explores the links between power, war, politics and violence. She informs the reader that power and violence are not the same; where one is absolute, the other cannot exist. Our research aim was to demonstrate how prescient her views were regarding the prognostication of the political animus that has occurred in America, especially through the evolution of technology. Our method in the the evaluation of this discourse was a line by line examination of the text of On Violence and assessing this evaluation against how the increasing attacks utilizing social platforms and cyber capabilities by U.S. competitors (foreign or domestic) are resulting in political vulnerability of the U.S. and the generally defined Western world. The public health security of American democracy is at risk through an inability, as individuals, to properly evaluate information, propaganda, misinformation, and disinformation from bad actors at home and abroad. Here we develop a perspective in which the political animus that started in the late 1960s becomes the foundation for our competitors' development of sophisticated methods of cyber subversion, and effective use of asymmetric conflict through manipulation of our own social media platforms in order to divide Americans and subvert effective government.
\end{abstract}

\section{Keywords}

Philosophy, Politics, Social Media, Violence, Conflict 


\section{Introduction}

We worry about jobs, the economy, politics, and our health, but do we adequately ponder violence, and how it affects our lives, or at least how its punctuated incidence wedges itself into our affairs? When referring to violence, we should go beyond the mugging that occurs around the corner or the school yard brawl or the fisticuffs at the local bar in the early hours of the morning. Instead, one must expand the definitional horizons to include the use of violence by groups that do not like what "we" think, and the use of violence by those that think like "us" and its use against "them." We are living in a time where there exists a great divide between many Americans, and the potential threat of violence by Americans towards Americans should be of great concern to all of us. These concerns are not new, especially when placed in the context of Hannah Arendt's nearly half-century old book, On Violence (Arendt, 1970a). Arendt wrote this important literary contribution in the midst of the Vietnam War, the United States (U.S.) student riots, and escalating racial tensions of the late-mid $20^{\text {th }}$ century. Her insights seem especially relevant and applicable to America's current state of affairs. Hannah Arendt was one of the great philosophers of the $20^{\text {th }}$ century (Williams, 2005). She spoke truth to power and raised many unpopular social questions and positions, and was concerned about the thoughtless embrace of science (Arendt \& Baehr, 2003; Fine, 2000, Berkowitz, 2019).

The 20th century was a century of wars and violent revolutions, and the $21^{\text {st }}$ century has not been off to a good start either, with major conflicts in Ukraine, Iraq, Afghanistan, and Syria. Violence is separate from power, force, authority and strength (Arendt, 1970a; Veck, 2015). Violence needs implements, i.e., weapons, bombs, broadly understood to be methods of death and destruction. Thankfully, the ultimate implement of violence, the nuclear bomb, has been held at bay because of the understanding of mutually assured destruction (Paul, 2009). Yet this "perfection" of the ultimate means of violence has led to public health security risks for society at large because of the emergence of other methods of attack such as the rise of cyber subversion and asymmetric warfare (also known as hybrid warfare), the two prongs of occasionally effective attacks on modern Western society that altogether avoids the methods of mass destruction.

Here are several important definitions provided by Arendt for this discourse (Arendt, 1970b):

- Power means to act in consort, but at a group level, and not at an individual level. Power stays in existence as long as the group remains together, but can be undone by violence. Power always stands in need of numbers, whereas violence, up to a point, can manage without them because it relies on implements.

- Strength is a property specific to an individual entity or a singular person. It 
is inherent in a thing or a being. "It belongs to its character, and may have a relation to other things, or persons, but it is independent of them (Arendt, 1970b)." Within the above contexts, it is in the nature of a group and its power to turn against independence, the fundamental property of individual strength.

- Force should be reserved for use to indicate the energy released by physical or social movements; it is not actually a synonym for violence.

- Authority is an elusive concept, and according to Arendt, "It can be invested in persons. It is the hallmark of unquestioning recognition by those who are asked to obey; neither coercion nor persuasion is needed (Arendt, 1970b)." The greatest enemy of authority is contempt.

- And finally, Violence can be identified by its use of instruments. The implements of violence are designed for the purpose of multiplying strength, until at the last stage of development they substitute for it.

Herein we present a discourse regarding how the increasing cyber capabilities of our competitors (foreign or domestic) may lead to political vulnerability of the U.S. and the generally defined Western world. We will also discuss the important aspects inherent to the above considerations, asymmetric conflict and public health security. The authors will attempt to present this discourse through Hannah Arendt's foresight, as presented in her 1960s and 1970s writings (Arendt \& Kohn, 2006; Macauley, 1996; Moyn, 2008; Papadimos, 2009), in regard to current political matters and social trends.

\section{Social Platforms and Cyber Subversion}

The enormous growth of productivity in the modern world was not accomplished by an increase in worker productivity, but almost exclusively to the development of technology, such as computers, artificial intelligence, and the Internet, and this productivity depended on neither the working class, nor the middle and upper-class bourgeoisie, but rather on scientists (Arendt, 1970c; Brynjolfsson \& Yang, 1996; Shujahat et al., 2019; Stawicki et al., 2018). The scientists, or at least the business men of science, have emerged as the "new intellectuals," and at the same time the emergence of new technologies has empowered the "traditional intellectuals" toward testing new boundaries (Arendt, 1970c; Kellner, 1997a, 1997b). Starting in the late 1960s, scientists ceased being a marginal part of society, and as Arendt brilliantly predicted, they would become the new elite. In 1960s these new elites were quite limited in their actions and vision, and less bound by clearly identifiable interests. They had no drive to organize and they lacked expertise in political matters. However, over the past 50 years their journey has been focused, evolutionary, and revolutionary (Corley, Kim, \& Scheufele, 2016; Kateb, 2017; Miller \& Adams, 2015; Mulkay, 1976; Zucker \& Darby, 1996). These "new intellectuals," through practical applications of science, technology, and the businesses they birthed, have become the revolutionary class, i.e., Bezos, Buterin, Gates, Jobs, Musk, Zuckerberg, etc. 
(Andrews \& Wood, 2013; Borins \& Herst, 2018). Over recent decades such intellectual, revolutionary minds have organized themselves (and their companies) into financial and social behemoths. And while back in the 1960s such people may have not had the experience in matters pertaining to power, that has all changed in the more recent past.

All of this scientific and intellectual intensity and energy has led to the creation of social platforms for communication among members of society, as well as organizations, and in doing so, has also created the opportunities for cyber subversion of these platforms. The digital age has forever changed how countries, organizations, and individuals conduct political warfare, prompting a reassessment of security priorities in democratic nations (Paterson \& Hanley, 2020). The utilization of cyberspace by state and non-state actors to subvert elections, encourage violence, and challenge the sovereignty, values, and the legitimacy of nations may result in both unpredictable and destabilizing consequences.

A social platform can be defined as a web-based technology that allows social media to be developed, managed, and the information presented to the platform users (such as Facebook or Instagram) (Techopedia, 2017). These platforms have user and technology-specific attributes, and allow communities to share content, add friends/other users, and set privacy controls, etc. Cyber subversion during the digital age has changed the manner in which nations can conduct political warfare by using and invading/subverting social platforms that the citizenry and organizations increasingly rely upon. This has led to the necessary fact that governments must address their security priorities continuously. Cyberattacks come in six forms: denial of service, pillage, subversion, masquerade, forgery, and disclosure (Smith, 2018). For purposes of this discourse we will consider all six of these forms of cyberattacks as cyber subversion. Each can be defined as follows. Denial of service involves temporary denial of the use of a computer or server through attacking data or a particular site with an abundance or overflow of traffic, as well as the use of ransomware. Pillage involves physically attacking the device/server; this could be considered more of a traditional sabotage event as opposed to a cyberattack. Subversion is usually represented by malware (software attack); this is not a physical attack (as in Pillage above). Masquerade is a manner of allowing attacks by making the attacker look like a legitmate actor thereby gaining access to software or the integrity of the computer or server. Forgery permits message modification or creation so that the receiver interprets the message as genuine. Discosures are confidentiality breakdowns. These threats will persist and evolve in the near and intermediate time fram as cyber protective measures are implemented.

In regard to the future ascent of technology and the transformational minds of this new scientific elite, Arendt indicated in 1969 that while she had every hope this new and revolutionary societal class could do much good for man- 
kind; however, she feared that their potential power could actualy become a detriment to society in general (Arendt, 1970c). Computers, the Internet, social media, online retailing, evolving smartphones, and new television network/streaming service giants have come into being (Brandt, 2011; Pavlik \& McIntosh, 2004; Stawicki et al., 2018; Watkins, Hjorth, \& Koskinen, 2012; Young \& Jude, 2004). Although these constructs and implementations of modern science and technology can do great things for societies, they also have become a cyber-nightmare for individuals, institutions, and governments (Alterman, 2011; Eltantawy \& Wiest, 2011). Unbeknownst to the brightest engineers, programmers, and politicians alike, the Internet revolution created the subtlest, yet extremely effective approach to the West's, and more specifically, America's underbelly. For what resulted was the "electronic door" to the minds of free men and women, many of whom have economic, social, political, racial, and gender biases regarding how well the great ship America is sailing, or how it should sail, or if it should sail at all. When that portable device's "electronic door" beeps, rings, or vibrates citizens let the information in, spending little time validating the messenger or the message (Metzger, Flanagin, \& Medders, 2010; Wu, Huberman, Adamic, \& Tyler, 2004). Perhaps equally concerning, people tend to search and are fully enabled to do so without any filters for the most agreeable explanation for their discomfort or the identification of an easy scapegoat (Beck, Pahlke, \& Seebach, 2014; Bryner \& Managing, 2010; Cross, Rice, \& Parker, 2001; Gerber, Hui, \& Kuo, 2012; Kasch, 2013; Hur \& Gupta, 2013; Wiederhold, 2013). Worse yet, as increasingly drone-like, "socially programmable beings" immerse themselves in "sterile communications," human empathy may be slowly becoming "a thing of the past (Bryner \& Managing, 2010; Hourcade \& Nathan, 2013; Sakamoto et al., 2014; Wiederhold, 2013).”

The Internet plutocracy has made available platforms that provide information to the masses that has been at times relatively unverifiable, spurious, and easily altered. This open gateway to the minds of a divided nation is fertile ground for disinformation by competitors (Norden \& Vandewalker, 2017; Stelzenmüller, 2017; Svetoka, 2016). What makes humans political beings is their faculty of action. In so doing they can band together and complete enterprises that cannot be accomplished individually thereby embarking on and completing projects that they could only dream of as individuals (Arendt, 1970c).

However, this "action" can be constructive or destructive, and there is a lot of "in between" as one man's good may be another man's evil. It is of note that violence and power are not naturally occurring in the animal kingdom; this is confined to the political sphere of humans and inherent to the intelligence with which humans are gifted (Arendt, 1970b). Arendt further advocates that neither reason nor consciousness separates man from animals, but the use of language. As such, deliberate and strategic use of language combined with the 
availability of the Internet as a platform, are bound to make a significant impact on society (Nguyen et al., 2017; Papacharissi, 2002; Pérez, 2016; Pérez \& Tavits, 2017). This is particularly concerning because U.S. power and information structures/infrastructures are becoming more centralized, and disinformation and the resulting fear and potential insecurity can cause further attempts at concentrating power, and in so doing the Federal government's authority may become exaggerated and even more centralized from a purely reactionary perspective. This, in turn, may overwhelm the power vested in individual States and create an immensely influential executive branch in a continuous feedback cycle. The end product could be the erosion of the power of Congress and the "people". Additionally, the larger a country becomes in terms of population and wealth and territory, greater is the need for a central administration and with that comes the anonymous power of administrators (Arendt, 1970c).

As the central government grows ever stronger, different segments of the country will view this as an offense. Yes, the central government should protect the rights of minorities and endorse diversity, but every decrease, or perceived decrease, in an individual's or group's power or rights, or that of an individual region of the country, will contribute to an ever increasing political/social rent in the well-established fabric of society. As we centralize, we grow our bureaucracies. In a matured anonymous centralized bureaucracy who will there be to argue with, to whom can you complain (Arendt, 1970c)? Will we have "a tyranny without a tyrant (Arendt, 1970c)?”

The point here is that the Internet is, and will continue to be, a format for invectives. It will continue to be a source of truth, half-truths, and non-truths. It will be a space of appearance where the fool, the villain, and the saint will present their arguments to their particular audiences with either absent or delayed verification of facts (Hermida, 2012; Stawicki et al., 2018). Those who seek to do this country (or any other country) ill, and those in this country who wish to do their brother and sister citizens ill, will largely be free to continue to act freely and potentially undermine the health of the country, the body politic, and the truth.

There are no absolute answers for combating the cyber subversion of America, its inhabitants, or its allies; done by others, or done by us to each other. This problem was prophetically postulated by Arendt 50 years ago and we failed to appreciate its potential to result in destructive political animus and any associated consequences. This threat and intrusion into our lives and our psyche puts us in harm's way, both physically and psychologically.

These cyber intrusions have lessened our power as a nation because we no longer can, or are less likely, to act in consort. Additionally, as citizens we have been weakened (through manufactured divisions) in our capability to act in counterbalance to our central government (peaceably) when it seeks to impose its will on some of us (at any particular time) or all of us (in punctuated fa- 
shion) (Dorsey \& Díaz-Barriga, 2015; Habermas, 2018; Locke, 1947). Power always stands in need of numbers. The enmity fomented on the Internet by various competitors mitigates our power, our strength, and the legitimate authority of our institutions of government (Barnes, 2018; Cohen, 2006; Hoey, 2007). The individual entity of strength is a historical, traditional element of the American character. It is the nature of our competitors to produce a message that acts against our independence in order to harm our individual strength. Force is not violence, but seems to have been unleashed and increasingly manipulated as social movements of the "American Right" and the "American Left" (Barber, 2016; Mason, 2018; Poole \& Rosenthal, 1984). These political forces are being harnessed by our competitors to weaken us. Authority is always elusive, but the contempt engendered by Americans of diverse backgrounds against one another and the Federal government through cyber subversion is extremely destructive and seductive at the same time. Our competitors wish this contempt to be not only against one another, but also for our elected officials and institutions. The organizations and governments using Internet platforms against the American people and government are hoping that their messages will cause some to resort to using implements of violence against each other. This, in turn, will further empower the malignant agents who instigate negative emotions, behaviors and social movements in the first place. Here, the awareness of the processes involved, and the education regarding human response(s) will be critical to minimizing harm. This vulnerability to our physical and psychological well-being allows our competitors to sew discord among us through an electronic vector that modulates both the perceived "truth" and one's emotional state (Bay, 2018; Singer \& Brooking, 2018). Furthermore, cyber intrusions into our lives in order to distribute falsehoods may lead to hesitation in both our actions and reactions, thereby augmenting the advantages of hostiles in their use of asymmetric conflict against America and the West on the world stage.

\section{Asymmetric Conflicts}

The definition of asymmetric conflict, according to the Merriam-Webster dictionary is, "warfare that is between opposing forces which differ greatly in military power and that typically involves the use of unconventional weapons and tactics (such as those associated with guerilla warfare and terrorist attacks) (Merriam-Webster Dictionary, 2019)." However, there are two perspectives to this definition. First, is the example of a small paramilitary force causing disruption, damage, death and fear among citizenry in the areas of direct control as well as indirectly abroad (Bussolati, 2015). This is usually through violence, and sometimes malignant actors can use cyber platforms for recruitment, propaganda, and actual electronic damage to infrastructure (Bussolati, 2015; Weimann, 2016; Zeitzoff, 2017). A second perspective of asymmetric conflict may also apply; if two (or more) great powers oppose each other, they may wish to confront 
each other in the cyber world thereby attempting to degrade one another without overt warfare. In a way, this may be considered a form of "indirect aggression." As a result, they achieve their aims politically and economically without bloodshed, or at least limiting any lethal confrontations (Bussolati, 2015; King et al., 2018). For example, Country A may have a more powerful Navy than Country B, and Country B may have a more developed army than Country A. However, Country B may worry about the Navy of Country A because of its ability to project might through their fleet. Therefore, Country B may use cyber platforms to degrade Country A's military capabilities to project naval power by fomenting political unrest, dissent, and confusion through disinformation at home or among allies (the assumption is that no nation state at this time wishes to use a nuclear option, although it may be an implied threat). This asymmetric approach has been utilized by a number of countries/organizations (Hickman et al., 2018).

In a way, the above approach will likely become the way of $21^{\text {st }}$ century conflict and intimidation (Banasik, 2016; Chen \& Dinerman, 2018; Erol, 2015). Of concern is the fact that asymmetric conflict obscures the differences "between civilians and combatants and demands and permits all activities deemed necessary to achieve success (Hickman et al., 2018)." This method of warfare is used by actors who do not believe in, or abide by established rule-based international systems and conventions (Hickman et al., 2018). Asymmetric conflict will use the hybrid approach in order to present numerous and integrated threats in targeting an opponent's identified vulnerabilities over an extended time frame, which includes movement of conventional forces, nuclear weapon threats, energy and economic intimidation, disinformation, propaganda, cyber disruption and destabilization (Bachmann, Gunneriusson, Hickman, Weissman, \& Nilsson, 2018). This method of warfare will use intermittent increases in intensity and synchronization through the implementation of military, political, economic, cyber, and information approaches or threats (Hickman et al., 2018, Bachman et al., 2018). So, what type of nation-state, or presumed/self-proclaimed entity, would use this particular approach? It is highly likely that such entities have certain elements in their strategic culture that reinforce this pattern of behavior (Hickman et al., 2018):

- They think they are a Great Power or force (political or religious, or economic, or scientific, or all of the above).

- They probably assert a Clausewitzian approach (Carl Phillip Gottfried von Clausewitz was a military theoretician, scholar, and General Officer in Prussia in the $19^{\text {th }}$ century) to warfare and believe in the utility of force.

- They believe they are permanently in conflict, and

- They believe they are technically inferior in some fashion, and therefore will sharpen their asymmetric/hybrid conflict approach to others they perceive as foes or competitors (Hickman et al., 2018). Of importance, all such countries or entities institute the same strategic culture. In either case, several military 
theoreticians espouse the perspective that, "we are in an era of post-modern warfare, where war is only if both sides say so," thereby reducing whether two opponents are "at war" to a matter of opinion (Hickman et al., 2018). This attitude is a source of political protection for parties and for individual politicians, as well as a country in general.

So why is America so vulnerable to asymmetric conflict at this time? It is a multifactorial argument, but a large part in this complex equation is determined by our political evolution over the past 50 years. What follows is a short background regarding Arendt's reflection on this matter as to why opportunities for asymmetric conflict against America may have been able to take root.

In brief, Arendt points out that a country that has grown in size and possessions needs to establish control through a central administration (Arendt, 1970c). Yet this centralization of power can lead to conflict among the positions of various citizen factions, as well as between those factions and the central government. In a way, a "balkanization" of the American electorate has occurred (Bobic, 2019; Cassese, 2019). This breach or "gap of disagreement," along with an inability to compromise, has invited an opportunity to make electronic, digital, and written manipulation an effective tool of disruption to the American political landscape. Arendt astutely pointed out the disadvantage of becoming a large country indicating that "bigness" has vulnerabilities in the ability to project and continues power in all but the smallest countries. Strength and resiliency can be destroyed in an insidious manner, and no one can establish at which point the system will break. This is a slow and subtle process that can be overlooked (Arendt, 1970c). And Arendt warned Western nations in 1969 of the rise of a new brand of nationalism, which many thought would usually assume would be to the "Right," but more probably is an indication of a burgeoning international resentment against "bigness" (Arendt, 1970c). Usually, ethnic groups in a nation would unite for the greater good, but in the 1960's a new "ethnic nationalism" began to come about which threatened the oldest and most established nations (Arendt, 1970c).

These observations of 50 years ago are still valid. More specifically, America continues to cede its authentic power through centralization of administration in that the Federal government has eroded State powers, and the executive power of the presidency has eroded the powers of Congress (Arendt, 1970c). As mentioned earlier in this discussion, larger countries accumulate more possessions, more objects, and therein is a need for more central administration (Arendt, 1970c). This growth and administration increasingly by a central authority has led to policies that cause disharmony among the electorate (ie, immigration, sustainability initiatives). These differences among members of the electorate allow, not only opportunities for asymmetric conflict, but for such an approach to be effective.

So, what opportunities exist for asymmetric conflict through cyber subver- 
sion that can affect the security of the public? It is simple, use our own information platforms against us. Asymmetric conflict uses the above-mentioned hybrid environment. The West has a free flow of information from itself to all corners of the world, and while the U.S. may see this flow of information as part of freedom and liberty, others view this as part of geopolitics and see the West as affecting their political systems and meddling (Hickman et al., 2018). Our adversaries, therefore, get access to our platforms and push back. These adversaries truly feel that there is "the lack of desire on the part of Western nations to engage in existential conflict due to their unwillingness to sacrifice their high standard of living," and Western countries accept and even facilitate their opponents "tactical truths" because the Western countries "choose not to call out disinformation as it would hurt their economic rationality (Hickman et al., 2018)."

It is important to note several definitions in regard to the use of language or words in this discussion. Propaganda consists of biased or misleading information that can be used to affect a population's perspective or to promote a political agenda. Misinformation is wrong information that is passed on without malice. However, disinformation in wrong, false and intentionally disseminated (Hickman et al., 2018). These three aspects of information transmission are utilized during an asymmetric conflict in the fight for the narrative pertaining to any particular situation. The problem is further compounded in this era of 24-hour news cycles and news channel competition, in conjunction with the advent of powerful social media platforms; and due to the rapidity of information flows, journalists are no longer able to confirm and verify facts as they have in previous decades thereby making false narratives easier to pass on to a naïve public (Cooke, 2017). This goes hand in hand with an interesting phenomenon known as "the continued-influence effect of misinformation" where certain citizenry relies on disinformation or misinformation even after it has been retracted (Brydges, Gignac, \& Ecker, 2018; Seifert, 2002). Such uncorrected deficits are rampant, and a threat to Western societies. As Arendt indicated to us, "Words can be relied on only if one is sure that their function is to reveal and not to conceal (Arendt, 1970c)."

\section{An Offset Strategy}

Compromising our public health security requires a solution, or offset strategy (Hicks \& Hunter, 2017). An offset strategy is a long-term competitive effort. It usually occurs during peacetime. It is an attempt to offset an opponent's advantage between wars or to avoid future wars, or to win them at a lesser cost. The U.S. has been involved in three offsets, historically. The First Offset occurred in the 1950s when the Soviet Union had an advantage over the U.S. geographically in Europe. The U.S. made nuclear weapons smaller and leaned on a nuclear advantage overall. The Second Offset occurred in the 1970s and 1980s when weapons were made super-precise so they would perform more 
effectively in joint battle networks. This occurred because of smaller integrated circuits, advanced information systems, and effective miniature sensor technologies. Most of the world has now caught up with the U.S. and consequently our military is looking into a Third Offset strategy in which the U.S. can work asymmetrically to exploit the weakness of others through an intellectual approach that uses multiple angles of defense and attack (for instance, new weapons technologies that can destroy multiple commercial drones used as lethal armament delivery systems).

Research into advanced technologies is important; we must now put together artificial neural networks that enhance human-machine collaboration and machine learning, and the use of big-data set analyses that can be accessed instantaneously. With regard to the battlefield, Western militaries are working on human-machine combat training and human-assisted operations (wearable electronics), but in the cyber world we must work hard to ensure our public's safety through an electronic platform offset methodology/technology that allows the U.S. and Western allies to create anti-access, area denial $\left(\mathrm{A}_{2} / \mathrm{AD}\right)$ strategies catered uniquely to that space $\left(\mathrm{A}_{2} / \mathrm{AD}\right.$ strategies are being employed across the world outside of cyber space, especially by the Chinese in the Western Pacific) (Locks, 2015). This type of combat, or competition, may use commercially available technologies and well as defense technologies. In the world of the Internet, Facebook, WhatsApp, Amazon, etc., we may need to more quickly look for a Fourth Offset strategy to protect the public. This Fourth Offset (however it may be configured) may be crucial because of the Internet-assisted Balkanization of the U.S., and an increased possibility of violence; "The practice of violence, like all action, changes the world, but the most probable change is to a more violent world (Arendt, 1970c)." Without an appropriate offset strategy, the U.S. public's health will be endangered by cyber platforms. The platforms used against the U.S. involve the engendering of hate, race, gender, politics, religion, ethnicity and regionalism. The Fourth Offset in the cyber world may require a system of cyber education for the common person that is attainable, where facts can be verified, where emotions can be quelled, and violence averted; in addition to technological advances.

This is a difficult proposition. While we can discuss or complain about corporate responsibility, political organizations' responsibilities, and governmental responsibility, in the end it is the personal responsibility of each individual citizen to foster an honest and questioning intellectual environment. Unfortunately, the hype and excitement caused by the circulation of malicious, salacious, and disruptive information available at the click of a button is hard to combat. While we have many excellent and effective technologies, we may have to fall back on something the ancient Greeks and Romans espoused, an education; one that involves self-examination and examination of the surrounding information environment (cyber or otherwise), along with electronic solutions. We need the reestablishment of critical 
thinking because it is essential to establish "truthiness" in order to combat our society's confrontation with the "production of confusion" in our information pursuits (Cooke, 2017).

This effort will need to occur in several layers, and cannot be accomplished overnight. In fact, it may take years. First, this educational effort regarding critical thinking will have to start with a reversal of federal, and to some extent, state government intervention in our school systems. Bell Hooks claimed that the innate curiosity of children for learning is smothered because, "the world around them becomes a passive process once they begin formal education (Hooks, 2010)." Our education system teaches young students to "consume information without question in an effort to educate them for conformity and obedience (Hooks, 2010)." Our system of state-wide exams ensures that education and topics are covered equally throughout the schools and regions, and have diminished a teacher's control of what is taught in the classroom. Teachers and students should "take back their right to independent thoughts and to reengage with critical thinking (Cooke, 2017)." This may be a hard sell to our current systems of central administration and bureaucracies. Nonetheless, we have to make our children smart, savvy, and questioning of all materials presented to them, for this is where the defense against cyber subversion starts, with the young.

And Hannah Arendt would agree that this has become a problem: "Whatever the administrative advantages and disadvantages of centralization may be, its political result is always the same: monopolization of power caused the drying up or oozing away of all authentic power sources in the country (Arendt, 1970c)." We are not confident, from the critical thinking and educational perspectives, that the American "experiment of centralized administration-the federal government overpowering state powers and executive power eroding congressional powers" has worked as effectively as once perceived (Arendt, 1970c).

Second, Nicole Cooke brings up the question of Multiple Literacy Instruction (MLI) wherein consumers should learn to make a few easy assessments (Cooke, 2017), (Table 1). Here we are speaking of a new $21^{\text {st }}$ century type of literacy. The type will not allow crops of young minds to be fooled. The tasks in Table 1

Table 1. Important basic assessments of information on Internet sites/social media platforms.

\footnotetext{
How recent is the information, or date of information

Examine Uniform Resource Locator (URL) site

Style of language, inflammatory, etc.

Credibility of information

Website reputation

Triangulation of information, i.e., locating same information on other websites

Adopted from NA Cooke. Posttruth, Truthiness, and Alternative Facts, Library Quarterly 2017; 87: 211-21.
} 
are not difficult, but learning to evaluate critical information may not be easy because of complexity and volume.

In regard to basic assessments of Internet sites/social media platforms it is of paramount importance that the information is recent and reliable. The Internet does not have enforceable standards and has many quality problems. The question of search engine technology being able to properly assess the enormous amount of questionable content and provide the user with correct and usable data is critically important. Improved quality algorithms would be useful to Internet users, especially when it relates to veracity or excluding disinformation or misinformation (Knight \& Burn, 2005). URL sites should always be examined as to their reliablility, credibility and reputation. They are repositories of information provided by individual people or organizations, and they should be evaluated as to trustworthiness and expertise. This is especially important as related to "credibility, including site design features, cross-media comparisons, source attributions and the role of users' reliance on web-based information (Flanagin \& Metzger, 2007).” Inflammatory language and style of language will always affect a reader and, as such, may present a powerful medium or tool to reach many audiences, thereby fomenting hate, recruiting converts, controlling images and narratives (Gerstenfeld, Grant, \& Chau-Pu, 2003). Finally, being able to find the information a reader desires should be verified through triangulation, i.e., verification on multiple websites (Winjhoven, \& Brinkhuis M, 2015). Unfortunately, all of the above approaches are far from being universally effective.

It is noteworthy that, for the first time in American history, $90 \%$ of Americans over 25 years of age have attained a high-school or more advanced level of education (U.S. Census Bureau); the U.S. population is more educated than ever before, and this bodes well for our Fourth Offset (Schmidt, 2018). Attainment of this educational level within a large population provides an excellent foundation to remedy information-based harm.

MLI is critical in the education of Americans' ability to intelligently decipher cyber information. Its components are: critical information literacy, digital literacy, and meta-literacy (Cooke, 2017). Critical information literacy involves not only examining the information provided on a particular website, but also who and what shapes that site's content and structure (Elmborg, 2006; Tisdell, 2008). Digital literacy is "about the mastery of ideas, not keystrokes (Cooke, 2017)." Cooke goes on to instruct us that metaliteracy is a holistic approach that involves the individual applying context to the information produced and then ingested. Cooke explains that, "Meta-literate learners are critically engaged researchers who can contribute to discourse and who can also successfully navigate the information landscape that is riddled with fake news, alternative facts, biases, and counter knowledge (Cooke, 2017)," which is misinformation packaged to look like facts that some subset of people will believe to be true (Thompson, 2008). Striving to make each citizen a meta-literate learner will be a daunting task. 
Finally, computer experts, and even friendly hackers will have to apply plug-ins to assist in discerning whether sites providing information to a consumer are reliable and verifiable (Cooke, 2017). This will require corporate, academic, and government participation, generally (unfortunately, a centralized aspect to solving the problem).

Hannah Arendt addressed her perception of a change that was in the offing. A change that would affect our public health and welfare, physically and emotionally that leads to the social and political dilemmas that threaten us as a nation. The schisms that have occurred in the "American fabric" lead us to a vulnerability in regard to cyber subversion and asymmetric (hybrid) conflict that has been enabled "bad actors" to work through the Internet and social media. However, there are offset strategies that are available for us to pursue: 1) through reclamation of the classroom by teachers, and 2) educational efforts and programs that are less centrally directed and that involve critical information literacy, digital literacy, and meta-literacy.

\section{Conclusion}

Hannah Arendt's On Violence gives the reader the instructive perspective that social media platforms may be manipulated by malicious players who wish to set the citizenry against one another, and that these platforms can be used against a society in an asymmetric manner through manipulation of culture, population diversity, and other prejudices. In doing so, there may be an increased propensity for violent confrontations. If people, through misinformation and disinformation perceive that they are losing an ability to govern themselves, or that a competitor will govern them, or fear each other because one group is assumed to be seeking advantage over another, then we are left with the potential for violence.

The public health security of a democracy may be at risk through the inability of citizens to properly evaluate information, propaganda, misinformation, and disinformation at home and abroad through our Internet and social media platforms. The prospect of violence in society, because of divisions or perceived divisions secondary to inabilities as a society to ferret out the truth from an electronic onslaught of information, is challenging. While Hannah Arendt had the ability and foresight to prospect our future possibilities and pitfalls as a nation, she only warned about the problems and consequences. The solutions are ours to find.

\section{Conflicts of Interest}

The authors declare no conflicts of interest regarding the publication of this paper.

\section{References}

Alterman, J. B. (2011). The Revolution Will Not Be Tweeted. The Washington Quarterly, 
34, 103-116. https://doi.org/10.1080/0163660X.2011.610714

Andrews, P., \& Wood, F. (2013). Uberpreneurs: How to Create Innovative Global Businesses and Transform Human Societies. Berlin: Springer.

https://doi.org/10.1057/9781137376152

Arendt, H. (1970a). On Violence. Boston, MA: Houghton Mifflin Harcourt.

Arendt, H. (1970b). On Violence. Part II. Boston, MA: Houghton Mifflin Harcourt.

Arendt, H. (1970c). On Violence. Part III. Boston, MA: Houghton Mifflin Harcourt.

Arendt, H., \& Baehr, P. R. (2003). The Portable Hannah Arendt. London: Penguin.

Arendt, H., \& Kohn, J. (2006). Between Past and Future. London: Penguin.

Bachmann, S.-D., Gunneriusson, H., Hickman, K., Weissman, M., \& Nilsson, N. (2018). Hybrid Threats and Asymmetric Warfare: What to Do? Conference Proceeding February 2018.

Banasik, M. (2016). Russia's Hybrid War in Theory and Practice. Journal on Baltic Security, 2, 157-182. https://doi.org/10.1515/jobs-2016-0035

Barber, M. J. (2016). Ideological Donors, Contribution Limits, and the Polarization of American Legislatures. The Journal of Politics, 78, 296-310.

https://doi.org/10.1086/683453

Barnes, J. (2018). US Begins First Cyberoperation against Russia Aimed at Protecting Elections. NY Times (Oct. 23, 2018).

Bay, M. (2018). Weaponizing the Haters: The Last Jedi and the Strategic Politicization of Pop Culture through Social Media Manipulation. First Monday, 23, 9388. https://doi.org/10.5210/fm.v23i11.9388

Beck, R., Pahlke, I., \& Seebach, C. (2014). Knowledge Exchange and Symbolic Action in Social Media-Enabled Electronic Networks of Practice: A Multilevel Perspective on Knowledge Seekers and Contributors. MIS Quarterly, 38, 1245-1270.

https://doi.org/10.25300/MISQ/2014/38.4.14

Berkowitz, R. (2019). About Hannah Arendt. http://hac.bard.edu/about/hannaharendt

Bobic, N. (2019). Balkanization and Global Politics: Remaking Cities and Architecture. London: Routledge. https://doi.org/10.4324/9781315162065

Borins, S., \& Herst, B. (2018). Negotiating Business Narratives: Fables of the Information Technology, Automobile Manufacturing, and Financial Trading Industries. Berlin: Springer.

Brandt, R. L. (2011). One Click: Jeff Bezos and the Rise of Amazon.com. London: Penguin.

Brydges, C. R., Gignac, G. E., \& Ecker, U. K. (2018). Working Memory Capacity, Short-Term Memory Capacity, and the Continued Influence Effect: A Latent-Variable Analysis. Intelligence, 69, 117-122. https://doi.org/10.1016/j.intell.2018.03.009

Bryner, J., \& Managing, L. (2010). Today's College Students Lack Empathy. LiveScience.Com. May, 28.

Brynjolfsson, E., \& Yang, S. (1996). Information Technology and Productivity: A Review of the Literature. In Advances in Computers (Vol. 43, pp. 179-214). Amsterdam: Elsevier. https://doi.org/10.1016/S0065-2458(08)60644-0

Bussolati, N. (2015). 'The Rise of Non-State Actors in Cyberwarfare. In Cyber War: Law and Ethics for Virtual Conflicts (pp. 102-126). Oxford: Oxford University Press. https://doi.org/10.1093/acprof:oso/9780198717492.003.0007

Cassese, E. C. (2019). Partisan Dehumanization in American Politics. Political Behavior, 1-22. https://doi.org/10.1007/s11109-019-09545-w 
Chen, J. Q., \& Dinerman, A. (2018). Cyber Capabilities in Modern Warfare. In Cyber Security: Power and Technology (pp. 21-30). Berlin: Springer. https://doi.org/10.1007/978-3-319-75307-2 2

Cohen, S. F. (2006). The New American Cold War. The Nation, July 10, 9-17.

Cooke, N. A. (2017). Post-Truth, Truthiness, and Alternative Facts: Information Behavior and Critical Information Consumption for a New Age. The Library Quarterly, 87, 211-221. https://doi.org/10.1086/692298

Corley, E. A., Kim, Y., \& Scheufele, D. A. (2016). Scientists' Ethical Obligations and Social Responsibility for Nanotechnology Research. Science and Engineering Ethics, 22, 111-132. https://doi.org/10.1007/s11948-015-9637-1

Cross, R., Rice, R. E., \& Parker, A. (2001). Information Seeking in Social Context: Structural Influences and Receipt of Information Benefits. IEEE Transactions on Systems, Man, and Cybernetics, Part C (Applications and Reviews), 31, 438-448. https://doi.org/10.1109/5326.983927

Dorsey, M. E., \& Díaz-Barriga, M. (2015). The Constitution Free Zone in the United States: Law and Life in a State of Carcelment. PoLAR: Political and Legal Anthropology Review, 38, 204-225. https://doi.org/10.1111/plar.12107

Elmborg, J. (2006). Critical Information Literacy: Implications for Instructional Practice. The Journal of Academic Librarianship, 32, 192-199. https://doi.org/10.1016/j.acalib.2005.12.004

Eltantawy, N., \& Wiest, J. B. (2011). The Arab Spring Social Media in the Egyptian Revolution: Reconsidering Resource Mobilization Theory. International Journal of Communication, 5 , 18.

Erol, M. S. (2015). Hybrid Warfare Studies and Russia's Example in Crimea. Gazi Akademik Bakış, 9, 261-277. https://doi.org/10.19060/gab.22813

Fine, R. (2000). Hannah Arendt: Politics and Understanding after the Holocaust. In R. Fine, \& C. Turner (Eds.), Social Theory after the Holocaust (pp. 19-45). Liverpool: Liverpool University Press. https://doi.org/10.5949/liverpool/9780853239659.003.0003

Flanagin, A. J., \& Metzger, M. J. (2007). The Role of Site Features, User Attributes, and Information Verification Behaviors on the Perceived Credibility of Web-Based Information. New Media \& Society, 9, 319-342. https://doi.org/10.1177/1461444807075015

Gerber, E. M., Hui, J. S., \& Kuo, P.-Y. (2012). Crowdfunding: Why People Are Motivated to Post and Fund Projects on Crowdfunding Platforms. The Proceedings of the International Workshop on Design, Influence, and Social Technologies: Techniques, Impacts and Ethics, Evanston IL, February 2012, Vol. 2, 10.

Gerstenfeld, P. B., Grant, D. R., \& Chau-Pu, C. (2003). Hate Online: A Content Analysis of Extremist Internet Sites. Analyses of Social Issues and Public Policy, 3, 29-44. https://doi.org/10.1111/j.1530-2415.2003.00013.x

Habermas, J. (2018). The Post-National Constellation: Political Essays. Hoboken, NJ: John Wiley \& Sons.

Hermida, A. (2012). Tweets and Truth: Journalism as a Discipline of Collaborative Verification. Journalism Practice, 6, 659-668. https://doi.org/10.1080/17512786.2012.667269

Hickman, K., Weissmann, M., Nilsson, N., Bachman, S.-D., Gunneriusson, H., \& Thunholm, P. (2018). Hybrid Threats and Asymmetric Warfare: What to Do? Stockholm 14-15 November, 2017, the Swedish Defence University, Stockholm, Sweden.

Hicks, K., \& Hunter, A. (2017). What Will Replace the Third Offset? Lessons from Past Innovation Strategies. 
https://www.defenseone.com/ideas/2017/03/what-will-replace-third-offset-lessons-past -innovation-strategies/136260

Hoey, J. H. (2007). The Global Reach of Chinese Soft Power: China's Rise and America's Decline?

Hooks, B. (2010). Teaching Critical Thinking: Practical Wisdom. New York: Routledge.

Hourcade, J. P., \& Nathan, L. P. (2013). Human Computation and Conflict. In Handbook of Human Computation (pp. 993-1009). Berlin: Springer.

https://doi.org/10.1007/978-1-4614-8806-4 77

Hur, J. L., \& Gupta, M. (2013). Growing Up in the Web of Social Networking: Adolescent Development and Social Media. Adolescent Psychiatry, 3, 233-244. https://doi.org/10.2174/2210676611303030004

Kasch, D. (2013). Social Media Selves: College Students' Curation of Self and Others through Facebook. UCLA.

Kateb, G. (2017). Utopia: The Potential and Prospect of the Human Condition. Abingdon-on-Thames: Routledge. https://doi.org/10.4324/9781351300407

Kellner, D. (1997a). Intellectuals, the New Public Spheres, and Techno-Politics. New Political Science, 41-42, 169-188.

Kellner, D. (1997b). Techno-Politics, New Technologies, and the New Public Spheres. New Political Science, 41-42.

King, Z. M., Henshel, D. S., Flora, L., Cains, M. G., Hoffman, B., \& Sample, C. (2018). Characterizing and Measuring Maliciousness for Cybersecurity Risk Assessment. Frontiers in Psychology, 9, 39. https://doi.org/10.3389/fpsyg.2018.00039

Knight, S., \& Burn, J. (2005). Developing a Framework for Assessing Information on the World Wide Web. Informing Science: The International Journal of an Emerging Transdiscipline, 8, 159-172. https://doi.org/10.28945/493

Locke, J. (1947). Two Treatises of Government: With a Supplement, Patriarcha, by Robert Filmer. New York: Simon and Schuster.

Locks, B. (2015). Bad Guys Know What Works: Asymmetric Warfare and the Third Offset.

https://warontherocks.com/2015/06/bad-guys-know-what-works-asymmetric-warfareand-the-third-offset

Macauley, D. (1996). Hannah Arendt and the Politics of Place: From Earth Alienation to Oikos. In D. Macauley (Ed.), Minding Nature: The Philosophers of Ecology (pp. 102-133). New York: Guilford Press.

Mason, L. (2018). Uncivil Agreement: How Politics Became Our Identity. Chicago, IL: University of Chicago Press. https://doi.org/10.7208/chicago/9780226524689.001.0001

Merriam-Webster Dictionary (2019). Asymmetric Warfare. https://www.merriam-webster.com/dictionary/asymmetric\%20warfare

Metzger, M. J., Flanagin, A. J., \& Medders, R. B. (2010). Social and Heuristic Approaches to Credibility Evaluation Online. Journal of Communication, 60, 413-439. https://doi.org/10.1111/j.1460-2466.2010.01488.x

Miller, A., \& Adams, J. (2015). The Influence of Emerging Administrative Scientists: An Interview with Anne Miller. The Journal of Nursing Administration, 45, 192-193. https://doi.org/10.1097/NNA.0000000000000183

Moyn, S. (2008). Hannah Arendt on the Secular. New German Critique, 35, 71-96. https://doi.org/10.1215/0094033X-2008-014

Mulkay, M. (1976). The Mediating Role of the Scientific Elite. Social Studies of Science, 6, 
445-470. https://doi.org/10.1177/030631277600600308

Nguyen, Q. C., McCullough, M., Meng, H.-W., Paul, D., Li, D., Kath, S., Smith, K. R. et al. (2017). Geotagged US Tweets as Predictors of County-Level Health Outcomes, 2015-2016. American Journal of Public Health, 107, 1776-1782. https://doi.org/10.2105/AJPH.2017.303993

Norden, L. D., \& Vandewalker, I. (2017). Securing Elections from Foreign Interference. New York: Brennan Center for Justice at New York University School of Law.

Papacharissi, Z. (2002). The Virtual Sphere: The Internet as a Public Sphere. New Media \& Society, 4, 9-27. https://doi.org/10.1177/14614440222226244

Papadimos, T. J. (2009). Reflective Thinking and Medical Students: Some Thoughtful Distillations Regarding John Dewey and Hannah Arendt. Philosophy, Ethics, and Humanities in Medicine, 4, 5. https://doi.org/10.1186/1747-5341-4-5

Paterson, T., \& Hanley, L. (2020). Political Warfare in the Digital Age: Cyber Subversion, Information Operations and "Deep Fakes". Australian Journal of International Affairs, 74, 439-454. https://doi.org/10.1080/10357718.2020.1734772

Paul, T. V. (2009). The Tradition of Non-Use of Nuclear Weapons. Stanford, CA: Stanford University Press. https://doi.org/10.1515/9780804771009

Pavlik, J. V., \& McIntosh, S. (2004). Converging Media: An Introduction to Mass Communication. Boston: Allyn \& Bacon.

Pérez, E. O. (2016). Rolling off the Tongue into the Top-of-the-Head: Explaining Language Effects on Public Opinion. Political Behavior, 38, 603-634. https://doi.org/10.1007/s11109-015-9329-1

Pérez, E. O., \& Tavits, M. (2017). Language Shapes People's Time Perspective and Support for Future-Oriented Policies. American Journal of Political Science, 61, 715-727. https://doi.org/10.1111/ajps.12290

Poole, K. T., \& Rosenthal, H. (1984). The Polarization of American Politics. The Journal of Politics, 46, 1061-1079. https://doi.org/10.2307/2131242

Sakamoto, M., Yoshii, A., Nakajima, T., Ikeuchi, K., Otsuka, T., Okada, K., Kobayashi, A. et al. (2014). Human Interaction Issues in a Digital-Physical Hybrid World. The 2014 IEEE International Conference on Cyber-Physical Systems, Networks, and Applications, Hong Kong, 25-26 August 2014, 49-54. https://doi.org/10.1109/CPSNA.2014.17

Schmidt, E. (2018). For the First Time, 90 Percent Completed High School of More. https://www.census.gov/library/stories/2018/07/educational-attainment.html

Seifert, C. M. (2002). The Continued Influence of Misinformation in Memory: What Makes a Correction Effective? In Psychology of Learning and Motivation (Vol. 41, pp. 265-292). Amsterdam: Elsevier. https://doi.org/10.1016/S0079-7421(02)80009-3

Shujahat, M., Sousa, M. J., Hussain, S., Nawaz, F., Wang, M., \& Umer, M. (2019). Translating the Impact of Knowledge Management Processes into Knowledge-Based Innovation: The Neglected and Mediating Role of Knowledge-Worker Productivity. Journal of Business Research, 94, 442-450. https://doi.org/10.1016/j.jbusres.2017.11.001

Singer, P. W., \& Brooking, E. T. (2018). LikeWar: The Weaponization of Social Media. New York: Eamon Dolan Books.

Smith, R. E. (2018). https://securityboulevard.com/2018/03/the-six-types-of-cyberattacks

Stawicki, T. T., Peck, G. L., Galwankar, S. C., Bahner, D. P., Papadimos, J. S., Stawicki, S. P., \& Papadimos, T. J. (2018). From "Pearls" to "Tweets": How Social Media and Web-Based Applications Are Revolutionizing Medical Education. International Journal of Academic Medicine, 4, 93. https://doi.org/10.4103/IJAM.IJAM $47 \quad 19$ 
Stelzenmüller, C. (2017). The Impact of Russian Interference on Germany's 2017 Elections. Testimony before the US Senate Select Committee on Intelligence June, 28.

Svetoka, S. (2016). Social Media as a Tool of Hybrid Warfare. Riga (Latvia): NATO Strategic Communications Centre of Excellence.

Techopedia (2017). Social Platform.

https://www.techopedia.com/definition/23759/social-platform

Thompson, D. (2008). Counter Knowledge. New York: WW Norton \& Company.

Tisdell, E. J. (2008). Critical Media Literacy and Transformative Learning: Drawing on Pop Culture and Entertainment Media in Teaching for Diversity in Adult Higher Education. Journal of Transformative Education, 6, 48-67.

https://doi.org/10.1177/1541344608318970

Veck, W. (2015). Arendt, Power and Education. In Power and Education (pp. 13-25). Berlin: Springer. https://doi.org/10.1057/9781137415356 2

Watkins, J., Hjorth, L., \& Koskinen, I. (2012). Wising Up: Revising Mobile Media in an Age of Smartphones. Continuum, 26, 665-668. https://doi.org/10.1080/10304312.2012.706456

Weimann, G. (2016). The Emerging Role of Social Media in the Recruitment of Foreign Fighters. In Foreign Fighters under International Law and Beyond (pp. 77-95). Berlin: Springer. https://doi.org/10.1007/978-94-6265-099-2 6

Wiederhold, B. K. (2013). Are "Facebook Murders" a Growing Trend? New Rochelle, NY: Mary Ann Liebert, Inc.

Williams, G. (2005). Hannah Arendt: Critical Assessments of Leading Political Philosophers. London: Routledge.

Winjhoven, F., \& Brinkhuis, M. (2015). Internet Information Triangulation: Design Theory and Prototype Evaluation. JASIST, 66, 684-701.

https://doi.org/10.1002/asi.23203

Wu, F., Huberman, B. A., Adamic, L. A., \& Tyler, J. R. (2004). Information Flow in Social Groups. Physica A: Statistical Mechanics and Its Applications, 337, 327-335. https://doi.org/10.1016/j.physa.2004.01.030

Young, M., \& Jude, M. (2004). The Case for Virtual Business Processes: Reduce Costs, Improve Efficiencies, and Focus on Your Core Business. Indianapolis, IN: Cisco Press.

Zeitzoff, T. (2017). How Social Media Is Changing Conflict. Journal of Conflict Resolution, 61, 1970-1991. https://doi.org/10.1177/0022002717721392

Zucker, L. G., \& Darby, M. R. (1996). Star Scientists and Institutional Transformation: Patterns of Invention and Innovation in the Formation of the Biotechnology Industry. Proceedings of the National Academy of Sciences, 93, 12709-12716.

https://doi.org/10.1073/pnas.93.23.12709 